Orbis Tertius, vol. XXVI, no 34, e214, noviembre 2021 - abril 2022. ISSN 1851-7811

Universidad Nacional de La Plata

Facultad de Humanidades y Ciencias de la Educación

Centro de Estudios de Teoría y Crítica Literaria

\title{
Tensiones en el archivo colonial latinoamericano: la crónica mestiza Relación de Texcoco (1582) de Juan Bautista Pomar
}

\author{
Tensions in the Latin American colonial archive: the mestizo chronicle Relación \\ de Texcoco (1582), by Juan Bautista Pomar
}

\author{
iD María Inés Aldao \\ inesaldao@hotmail.com \\ Instituto de Investigaciones en Humanidades y \\ Ciencias Sociales (UNLP - CONICET). Facultad de \\ Humanidades y Ciencias de la Educación. Universidad \\ Nacional de La Plata, Argentina \\ Universidad de Buenos Aires, Argentina
}

Recepción: 15 Abril 2021

Aprobación: 08 Agosto 2021

Publicación: 01 Noviembre 2021

Cita sugerida: Aldao, M. I. (2021). Tensiones en el archivo colonial latinoamericano: la crónica mestiza Relación de Texсосо (1582) de Juan Bautista Pomar. Orbis Tertius, 26(34), e214. https://doi.org/10.24215/18517811e214

\begin{abstract}
Resumen: En este artículo se responden algunos interrogantes respecto del sujeto de la enunciación del complejo grupo cronístico colonial denominado "crónicas mestizas" a través del análisis de uno de sus textos más representativos, Relación de Texcoco (1582) del cronista mestizo texcocano Juan Bautista Pomar. Además de ser una crónica pocas veces abordada desde una perspectiva literaria, este texto, cuyo original se encuentra perdido y del que se conservan apenas algunos capítulos, es ejemplo de las tensiones y arbitrariedades que subyacen al archivo colonial latinoamericano.

Palabras clave: Tensiones, Archivo, Crónica Mestiza, Relación de Texcoco, Juan Bautista Pomar.
\end{abstract}

\begin{abstract}
In this article I intend to address the issue of subjects of enunciation in the complex colonial chronicle group called "mestizo chronicles" through the analysis of one of its most representative texts, Relación de Texcoco (1582), written by the Texcocan mestizo chronicler Juan Bautista Pomar. Besides having rarely been studied from a literary perspective, this text, whose original copy is lost and from which only a few chapters remain, is the perfect example of the tensions and arbitrariness that underlie the Latin American colonial archive.
\end{abstract}

Keywords: Tensions, Archive, Mestizo Chronicles, Relación de Texcoco, Juan Bautista Pomar.

\section{INTRODUCCIÓN}

En la cronística colonial existen textos que relatan parte de la historia de los pueblos precolombinos y de la conquista de México desde una particular visión que fusiona el uso de fuentes indígenas con la retórica occidental. Estas crónicas mestizas que, paradójicamente, no siempre están escritas por cronistas mestizos, ponen en escena la oscilación constante entre ambas tradiciones que da origen a una nueva identidad, producto tensionado de las otras. Al leerlas, surgen varias preguntas respecto de su sujeto de la enunciación: ¿por qué se origina ese relato y a quién o quiénes va dirigido?, ¿cómo se narra aquello que no se ha vivido? Pero también, ¿cómo nombran estas crónicas al otro?, ¿quién es ese otro?, ¿cómo nombrar(se) a uno mismo?

En el transcurso de este trabajo analizo algunas respuestas a estos interrogantes centrándome en una de las crónicas mestizas más abordadas desde lo argumental pero, a la vez, menos estudiada desde su posicionamiento enunciativo. Me refiero a Relación de Texcoco (1582) del cronista texcocano Juan Bautista 
Pomar. En su evocación del pasado precolombino, su enunciación desde un ambiguo yo, su crítica hacia aspectos precisos del accionar conquistador en Nueva España y desde una aparente e inquietante sencillez, Relación de Texcoco es ejemplo de la complejidad retórica de toda crónica mestiza.

\section{BREVE APUNTE SOBRE LAS CRÓNICAS MESTIZAS}

De las posibles conceptualizaciones que refieren al término "crónica mestiza", tales como "literatura mestiza" (Cornejo Polar, 1994), "discurso transcultural" (Velazco, 2003), "discurso o mestizaje historiográfico" (Romero Galván, 2003; Pastrana Flores, 2009) o “crónica indígena” (Inoue Okubo, 2007), por señalar algunos, me inclino por la propuesta de "La crónica mestiza en México y el Perú hasta 1620: apuntes para su estudio histórico-literario" de Martin Lienhard (1983). En dicho artículo, retoma Historia de la literatura nábuatl (1953-1954) de Ángel María Garibay y plantea que las crónicas mestizas son un "grupo de textos que, casi independientemente del origen étnico de sus autores, reelaboran materiales discursivos o reales de la historia americana a través de unos procedimientos narrativos (verbales y/o pictográficos) de tradición heterogénea (indígena y europea)” (1983, p. 105). Estos textos difieren de la crónica europea sobre asuntos americanos, a la que el autor llama "producción de transición", y de la crónica (mitológica) indígena. Las crónicas mestizas, propone Lienhard, están ligadas a los centros de poder colonial que habían sido capitales indígenas (Tenochtitlan, Tezcoco, Tlaxcala, Cuzco) y pueden estar escritas en español o en náhuatl. ${ }^{1}$

Las crónicas mestizas son textos pertenecientes a la cronística colonial latinoamericana compuestos a partir de mediados del siglo XVI por sujetos coloniales inmersos en la posconquista y en la reorganización de la "sociedad colonial" (Cfr. Gruzinski, 2007a, p. 86). Dichos textos establecen cruces temáticos con las crónicas de tradición occidental, un estilo semejante y juicios de valor similares. Producen, así, un discurso similar al del conquistador y al del misionero, pero no idéntico.

Estas crónicas describen el origen del que descienden los cronistas, relato que, en muchos casos, constituye un verdadero panegírico. Si bien en ellas la adhesión a lo indígena y lo español es ambigua, la adscripción al cristianismo es categórica. Además, presentan una visión condenatoria pero, en general, suavizada de los horrores de la conquista. De esta manera, ponen en primer plano hechos y personajes que las crónicas de tradición occidental silencian. Asimismo, reescriben la historia de la conquista e incluyen los elementos de las tradiciones indígena y occidental en distinta proporción según los intereses de cada cronista mestizo y del contexto de producción y circulación textual. Fuertemente arraigadas a lo pictórico (rasgo proveniente de la tradición indígena), a su vez destacan el papel de algunos conquistadores, como Hernán Cortés para el caso novohispano. Es así como ofrecen versiones alternas de la historia de la conquista que difieren enormemente de la de los soldados cronistas. Son, así, reversiones, revisiones, historias nuevas que critican a la conquista y al relato de dicha gesta.

Por último, y sin que esto pretenda agotar la discusión, presentan un sujeto de la enunciación tan complejo como oscilante que entrelaza voces opuestas, que oscila en su objeto de repudio, que se inscribe incómodamente desde un yo que solo se inscribe en un nosotros "cristiano". Esta ambivalencia, que es, a la vez, una táctica textual, ha producido lecturas de las crónicas mestizas como simples fuentes de información sobre la "sociedad colonial" o el pasado indígena sin atender a sus posicionamientos enunciativos. Paradojas del archivo colonial, estas crónicas amputadas y diseminadas por distintas bibliotecas del mundo, han sido leídas desde una única perspectiva que desatiende la que quizá sea su peculiaridad más representativa, esto es, la siempre presente e irresoluta tensión del sujeto que enuncia. 


\section{UN SUJETO EN TENSIÓN}

Como planteé en la Introducción, Relación de Texcoco de Juan Bautista Pomar $^{2}$ ha sido poco atendida por la crítica, con algunas excepciones. ${ }^{3}$ Escrita a pedido de la Instrucción y Memoria de $1577^{4}$ y finalizada hacia 1582, está compuesta por la introducción y treinta y un capítulos de variada extensión, aunque las copias que se conservan hoy día comienzan por el capítulo XI y carecen de los capítulos XXVIII y XXIX. El texto culmina de manera abrupta, lo que puede indicar que la crónica terminaba con un cierre que, al igual que las pinturas y los apartados iniciales, se ha perdido. Fue publicada por primera vez en 1891 por Joaquín García Icazbalceta. El original se encuentra extraviado. Sólo queda una copia del manuscrito en la Universidad de Austin (Texas).

Se cree que Pomar ha escrito tres textos: la crónica mestiza Relación de Texcoco, un conjunto de poemas en náhuatl conocido como Romances de los señores de Nueva España (ca. 1585) y, por último, fuera del ámbito literario, una relación presentada con el objetivo de conseguir el legado de su bisabuelo, el tlatoani y poeta texcocano Nezahualcoyotl. ${ }^{5}$

Algunos críticos han destacado de Relación de Texcoco solamente la alabanza hacia el pueblo texcocano o la han catalogado injustamente como "de calidad literaria discutible o ínfima" (Vázquez Chamorro, 1991, pp. 7,19$)$. Lejos de estas consideraciones, propongo pensarla como un texto representativo del discurso de toda crónica mestiza, un discurso en tensión permanente entre dos tradiciones y en su propia enunciación. El enunciador de esta crónica transmite una interesante documentación de las historias que le son narradas, severos juicios hacia españoles y ciertas zonas de la cultura indígena, y una percepción particular acerca de los procesos de colonización y transculturación. A su vez, su carácter de mediador entre los ancianos texcocanos y los funcionarios de la Corona española produce un entrecruzamiento entre lo contado y lo respondido, transformando el relato en escisión y, al mismo tiempo, en estrecha relación entre lo indígena y lo español.

Por momentos, el enunciador pareciera estar más a gusto dando cuenta de la información sobre la ciudad, sus habitantes y costumbres, verdadero viaje a la "memoria indígena" (Florescano, 1999), tal como solicitaba la Instrucción, en lugar de pormenorizar el "presente" de la Colonia, datos que también debía proporcionar según el cuestionario. Este movimiento de acercamiento a la cultura originaria se realiza a través de diversos ejes. En primer lugar, las permanentes referencias a las fuentes indígenas que le permitieron recopilar la información necesaria para la relación. Según el enunciador, esta investigación se hizo "habiendo primero hecho muchas diligencias para ella, buscando indios viejos y antiguos inteligentes (...) y cantares antiquísimos" (Pomar, 1991, p. 21). En segundo lugar, un intento de objetividad como cronista capaz de diferenciar lo bueno y lo malo de sus antepasados. El enunciador distingue algunas costumbres "horrendas" como los sacrificios, pero no deja de relevar el papel del arte entre los indígenas o de destacar las antiguas formas de justicia en Texcoco. Además, toma partido por el pueblo indígena en general. Dice en distintas oportunidades, por ejemplo, que "los indios son muy domésticos y pacíficos unos con otros" (p. 71) y que "eran fidelísimos y constantes en toda adversidad" (p. 80). Así, presenta ese virtuosismo que caracterizaba a Texcoco dejando entrever que la causa de su actual decadencia es el proceso de colonización que arrasó, entre otras cosas, con aquella cultura.

\section{EL SEÑORÍO EXTINTO}

Dentro de esta reapropiación de la tradición indígena, el enunciador recupera el pasado de Texcoco desde una visión panegírica. Sin embargo, su objetivo no es solamente revalorizar el prestigio de su pueblo (exaltado en el transcurso de la crónica) para obtener las mercedes que reclama sino también contrarrestar las típicas acusaciones de los españoles a los indígenas: la ebriedad, la lujuria, el despotismo de sus monarcas, la crueldad de las guerras, la vagancia, entre otras. 
La descripción de Texcoco se inicia con la mención al carácter de sujeción de la misma. El enunciador plantea que, si bien es "pueblo poblado de indios y una de las tres cabeceras de la Nueva España, está encomendada a la Corona Real” (Pomar, 1991, p. 23). Está situada a tres leguas de México, por vía de una laguna que las separa aunque, en definitiva, une. En un claro cruce con los procedimientos occidentales, el enunciador explica la etimología del nombre de la ciudad: hay a una legua un cerro llamado "Tetzcotl" en lengua chichimeca; luego, según el autor, los culbuaque "corrompieron" el vocablo por "Tezcoco" y el cerro "Tezcotzinco". Destaca que, finalmente, se desconoce su verdadero significado porque los chichimecas, habitantes originarios del lugar, se han acabado. ${ }^{6}$ Entonces, resultado de una imposición, tergiversación y luego pérdida del significado original: Texcoco surge tan ambigua como la identidad misma del mestizo. Y estos comentarios etimológicos que, al parecer, emulan las crónicas de tradición occidental, son críticos hacia la voracidad de toda conquista que arrasa tanto con los originarios como con la cultura del lugar, gesto que también podemos observar en las crónicas misioneras de Motolinía y Mendieta.

Las alusiones a Texcoco siempre están, en el texto, relacionadas con la distancia, los lazos, el comercio con México, rasgo de sumisión / sujeción que aún mantiene con la gran urbe. Es una ciudad que padece una doble colonización: la española y la que aún no ha sido eliminada, al menos del plano discursivo, y que se mantiene desde la preconquista: la de Tenochtitlan. Pero es de la ciudad de Texcoco en tanto señorío extinto que Pomar realiza un panegírico. ${ }^{7}$ La antigua Texcoco es una ciudad en la que se castigan los pecados y se enjuicia al que delinque; las guerras se producen sólo si son concertadas con México y Tacuba y hay, también, espacio para el arte. Esto se observa en la forma en que el enunciador resalta la relevancia de los versos y cantos para la perpetuación de la memoria:

Esforzábanse los hombres, y aun los plebeyos, si no eran para la guerra, para valer y ser sabidos y componer cantos en que introducían por vía de historia muchos sucesos prósperos y adversos, y hechos notables de los reyes y de personas ilustres y de valer; y el que llegaba al punto de esta habilidad era tenido y muy estimado, porque casi eternizaba con estos cantos la memoria y fama de las cosas que en ellos componían, y por esto era premiado no sólo del rey, pero de todo el resto de los nobles (p. 66).

Es esta una forma de aludir a la importancia de la historia como transmisora de cultura, con lo que pretende también destacar su crónica y, así, incidir en la obtención de aquello que reclama. Dice, además, que sin esas historias han quedado "como a escuras sin noticia ni memoria de los hechos de sus pasados" (p. 23). No será la única vez que el narrador utilice la dualidad oscuridad / luz para referirse a la falta de información y de memoria. La metáfora de la luz o "lumbre" como acercamiento o descubrimiento del pasado se encuentra también en otras crónicas mestizas, como las Historias de Cristóbal del Castillo (2001).

Según la Relación, los gobiernos de Nezahualpilli y Nezahualcoyotl fueron una suerte de edad de oro para el pueblo: tlatoque rectos, valerosos, pacíficos, injustamente olvidados (Pomar, 1991, p. 28), a pesar de haber sujeto diversos pueblos, estrategia con la que justifica las conquistas que culminan con la imposición de la religión del vencedor. Estos monarcas cesaban las guerras en caso de hambrunas, brindaban renta para ayudar al pueblo, no cometían excesos y los castigaban en los demás. En un intento de equiparación de las jerarquías, el narrador hace hincapié en que los tlatoque no eran del todo diferentes al hombre común: comían prácticamente lo mismo, adoraban los mismos ídolos, todos recibían enseñanza. Eran sumamente amados y respetados, tanto así que muchos súbditos (entre ellos, algunas de sus mujeres y de sus colaboradores cercanos) ante su muerte elegían ser enterrados junto a ellos (p. 63). Los tlatoque tenían esclavos a su servicio a quienes trataban con amabilidad y respeto (p. 68), mención repetida en varias ocasiones que contrasta con la reducción a la servidumbre del indígena por parte del español que el enunciador, como veremos, repudia.

El esfuerzo por homologar este antiguo señorío texcocano con el cristianismo es notable, movimiento que observamos también en otras crónicas mestizas. El narrador de la crónica asevera que los tlatoque "dudaban de que unos bultos de palo y piedra fueran dioses” (p. 48) y afirma que Nezahualcoyotl, espiritualidad y poemas mediante, fue quien más buscó al "verdadero dios" (p. 48). Afirma, también, que los texcocanos eran monoteístas en forma incipiente, de aquí que nombre, en el transcurso del texto, solamente tres de 
sus muchos ídolos (Huitzilopochtli, Tezcatlipoca y Tlaloc), omitiendo deliberadamente la descripción del vastísimo panteón de deidades indígenas que sí consignan, por ejemplo, las crónicas de tradición occidental. Además, describe algunas celebraciones, como la del casamiento, de manera muy similar al tipo de festividad que realizaban los españoles (p. 50) y hace hincapié en que los texcocanos castigaban el adulterio, el incesto (p. 52) y la sodomía (pp. 67, 68) con severidad.

Texcoco es representada como una ciudad armoniosa, que irradia justicia: las leyes, ordenanzas "y buenas costumbres y modos de vivir que generalmente se guardaba en toda la tierra procedían de esta ciudad" ( $\mathrm{p}$. 70), señala, en forma hiperbólica, el enunciador. A pesar de las guerras que mantenían con otros pueblos (las concertadas no son criticadas, las otras son prácticamente elididas de la descripción), vivían "pacíficos unos con otros" (p. 71). El panegírico de su pueblo llega al punto en que, según el narrador, los texcocanos no temían la muerte sino hacer algo "infame o afrentoso" (p. 80). Las únicas menciones negativas a otros pueblos son la adjudicación de la introducción de los sacrificios (casi la única referencia de desaprobación hacia el pasado texcocano) por parte de los mexicas (p. 39) y la crítica a la vestimenta de mexicas, tlaxcaltecas y huexotzincas: subraya el narrador que, mientras los tlatoque texcocanos vestían "muy honestos", los de los otros pueblos iban "arreados a la soldadesca y fanfarronamente” (p. 70), contrastando así la austeridad, virtud fundamental para el cristiano, con el orgullo o vanagloria, uno de los pecados capitales.

Pomar realiza, así, un recorrido por la memoria con estrategias retóricas del discurso de tradición occidental como el panegírico para alabar su ciudad y aludir, también, a la conformación actual. El cronista mestizo, entonces, recupera aquellos rasgos de la ciudad de sus antepasados que le permitirán destacar lo que le parece más (o lo único) elogiable de la Colonia, esto es, la introducción de la evangelización. El panegírico tiene, precisamente, la función de justificar la conquista y lo hace mediante este discurso transcultural que emerge de una relación compleja entre raigambre y cultura impuesta. Pero, también, critica sutilmente (dado el contexto de producción y circulación textual) su presente colonial, tan confuso y ambiguo. Entonces, si al describir su “presente" el mestizo no puede sino ver caos, ${ }^{8}$ la armonía que rigió en la antigua Texcoco pareciera comenzar a revivir en la Texcoco actual, sujeta, caótica, pero evangelizada.

\section{"MUY PEOR QUE SI FUERAN ESCLAVOS": DENUNCIAR LA CONQUISTA}

Una de las más fuertes denuncias a las consecuencias de la conquista española es la desaparición, extirpación y quema de pinturas que redundó, entre otras cosas, en falta de información, en falta de “memoria”, así como la amputación de aquellos "cantos antiguos que hoy se saben a pedazos" (p. 48). Siglos después, el mismo texto sigue evidenciando la falta: como he indicado con antelación, el manuscrito que se conserva de la Relación contenía pinturas que se encuentran extraviadas. Esta memoria escindida se transforma en lamento continuo a lo largo de la crónica asociada tanto a la imposibilidad de cumplir con la obligación de cronista como a la dificultad de situar y comprender ese pasado que estaba siendo olvidado (Inoue Okubo, 2000, p. 220).

No obstante, el juicio de valor más fuerte que encontramos en el texto es contra los conquistadores y el maltrato que sufren por parte suya los indígenas. A diferencia de otros cronistas, como Diego Muñoz Camargo, Pomar no señala a las pestes y enfermedades como causantes de la violenta desaparición de la población indígena en Nueva España sino que propone otra hipótesis:

Si hay alguna causa de su consumición es el muy grande y excesivo trabajo que padecen (los indígenas) en servicio de los
españoles, en sus labores, haciendas y granjerías, porque de ordinario en cada semana se reparten para este efecto mucha
cantidad de ellos en todos los pueblos de esta Nueva España, porque en todos los lugares de ellos tienen edificios, haciendas
y granjerías de pan, ganados, minas y ingenios de azúcar, caleras y otras muchas maneras y suertes de ellas, que benefician y
labran con ellos, que para ir a ellos a doce y a quince leguas de sus casas son compelidos y forzados, y que de lo que padecen
allí de hambre y cansancio se debilitan y consumen de tal manera los cuerpos, que cualquiera y liviana enfermedad que les de
basta para quitalles la vida, por el aparejo y de la mucha flaqueza que en ellos halla, y más de la congoja y fatiga de su espíritu,
que nace de verse quitar la libertad que Dios les dio, sin embargo, de haberlo así declarado S. M. por sus leyes y ordenanzas
reales para el buen tratamiento y gobierno de ellos, afirmando que del descontento de su espíritu no podía prevalecer con 
salud el cuerpo, y así andan muy afligidos, y se parece muy claro en sus personas, pues por defuera no muestran ningún género de alegría ni contento, y tienen razón, porque realmente los tratan muy peor que si fueran esclavos (Pomar, 1991, pp. 82-83).

Esta cita, la única de este tenor en toda la crónica (mejor: en lo que de ella se conserva), pone de manifiesto varias cuestiones. En primer lugar, una fuerte crítica a la reducción del indígena al servilismo por parte del español, muy similar a la que realizan los frailes en sus crónicas, pero poco común en otras crónicas mestizas, puesto que dicha osadía podía ser mal vista entre los funcionarios coloniales e, incluso, sus superiores, quienes deciden la restitución de tierras o servicios a los mestizos que luchan por ellos. ${ }^{9}$ En segundo lugar, un enunciador analítico que entiende de cuestiones médicas y asocia la debilidad con la inexorable introducción de la enfermedad (las pestes, en este caso) en un cuerpo doliente. (Recordemos que Pomar contaba con conocimientos de medicina (Acuña, 1986, p. 35). En tercer lugar, la eximición de culpa que hace a Felipe II por el maltrato de los indígenas: los españoles que esclavizan no representan, afirma el narrador, la voluntad real. Por último, la interpretación de que la conquista española devino en una sociedad no del todo justa, muy distinta a la sociedad texcocana ya extinta.

A pesar de lo elocuente de la cita, no debemos olvidar el objetivo que persigue Pomar: su cuestionario será leído por las autoridades coloniales antes de, si tiene suerte, llegar a manos del rey, aunque no existe información de que esto haya sucedido. Entonces, podemos pensar que esta dura crítica a la falta de reconocimiento del prestigio texcocano por parte de los españoles y sus ofensas es, también, advertencia sutil acerca de un posible desaire al dar a conocer sus reclamos. Es decir, Pomar se manifiesta en contra del maltrato (aunque de otro orden) que supondría la indiferencia ante sus pedidos. He aquí una de las tantas paradojas del mestizo: la labor escrituraria que emprende para posicionarse del "lado español" lo aproxima, en realidad, a la tradición indígena. Por esto, si bien algunos críticos (Inoue Okubo, 2003, p. 4) plantean que Pomar no se identifica con el pueblo texcocano, considero que, por el contrario, los procedimientos utilizados manifiestan un enunciador más oscilante que claro al respecto. Si bien su identificación con la parte indígena no es total, tampoco se presenta como un español más. En todo caso, en una crónica mestiza la identificación dista de ser terminante y se manifiesta como un proceso inacabado.

\section{LOCUS EN TENSIÓN}

Ser mestizo implica una identidad múltiple que produce un discurso en el que esa multiplicidad se pone de manifiesto y en el que inciden objetivos, intereses y adhesiones ideológicas. El enunciador de una crónica mestiza reclama, denuncia, aboga por mantener y obtener beneficios. Pero, también, rescata "su" historia de "la Historia". Como podemos observar, el locus representa la tensión implícita a toda crónica mestiza. En un estudio contrastivo del texto de Pomar con otras crónicas del período (incluso con otras crónicas mestizas) muestra que las tensiones enunciativas siempre están presentes en torno a ambas tradiciones aunque nunca de la misma manera ni con la misma intensidad.

El lamento por lo que ya no está inicia un movimiento descriptivo. En Relación de Texcoco, lo que más se describe es aquello irrecuperable. De aquí que la mayor parte del texto esté dedicada al relato del pasado indígena. Más allá de que las preguntas del cuestionario guían a Pomar a brindar dichos datos, hay una opción por el rescate de la memoria ya que el aporte de información podría haberse resuelto sin detalles excesivos ni intervenciones críticas.

A pesar de la inserción de pasajes en los que el enunciador se erige como portavoz de los nobles texcocanos, su visión sobre ese pasado oscila entre el repudio a sus prácticas paganas y el panegírico que incluye mucho de la nostalgia de la (no tan) paulatina desaparición. Este hecho de fundar su saber en fuentes orales indígenas aleja al mestizo del discurso occidental y lo inserta en una compleja dialéctica: los cronistas mestizos recurren a la cultura originaria mediante estrategias occidentales para que el saber redunde en un discurso occidentalizado que, en forma y contenido, avale y sutilmente, critique el presente colonial. Más que cercano a ese pasado 
texcocano o al presente colonizado, su enunciador manifiesta un lugar alternativo: el del servidor que se atiene a las condiciones nuevas de la ciudad (buscando claramente una cómoda inserción) pero que no se identifica del todo con ella. De esta forma, los mestizos pretenden adecuarse a una "sociedad" que los absorbe y rechaza, a la vez, por no pertenecer del todo a ninguna de las dos culturas. Esta situación incómoda se manifiesta en su discurso atravesado por ambas tradiciones que es, en realidad, el discurso de una nueva identidad.

Las crónicas mestizas, amputadas, diseminadas, fragmentadas, tienen como elemento constitutivo la tensión, ya sea en las tradiciones que las componen, en la complejidad enunciativa, en la diversidad de sus recursos retóricos e, incluso, en sus posicionamientos ideológicos. A pesar de su existencia en pedazos, de su desenfrenada dispersión y de la convivencia tensionada de sus componentes, o mejor, quizá por eso, podemos pensarlas como textos representativos del archivo colonial latinoamericano.

\section{REFERENCIAS}

Acuña, R. (1986). Introducción. Relaciones geográficas del siglo XVI: México. Tomo Tercero (pp. 23-45). México: Universidad Nacional Autónoma de México.

Aldao, M. I. (2020). Crónicas mestizas. En B. Colombi (Coord.), Términos criticos y palabras clave en la literatura latinoamericana. Buenos Aires: Colihue.

Álvarez, D. E. (1998). El panegírico poético latino a partir de Augusto: algunas calas. Myrtia, 13, 151-175.

Añón, V. (2011). Memoria rota, tensión y armonía en crónicas mestizas novohispanas. Orbis Tertius, 16(17), 1-9.

Benavente, T. de [Motolinía] (1985 [1541]). Historia de los Indios de la Nueva España. Madrid: Castalia.

Castillo, C. del (2001). Historia de la venida de los mexicanos y de otros pueblos e Historia de la conquista. México: Conaculta.

Cesareo, E. (1936). Ilpanegirico nella Poesía latina. Palermo: Via Catania.

Cornejo Polar, A. (1994). Mestizaje, transculturación, heterogeneidad. Revista de Crítica Literaria Latinoamericana, 20(40), 368-371.

Diccionario de la Real Academia Española. (2017). Madrid: Asociación de Academias de la Lengua Española.

Diccionario Nauatl-Español / Español-Nauatl. (2001). México: Biblioteca de los Pueblos Indígenas-Instituto Mexiquense de Cultura.

Espericueta, J. (2015). Writing virtue and indigenous rights: Juan Bautista Pomar and the Relación de Texcoco. Hispania, 98(2), 208-219.

Florescano, E. (1999). Memoria indígena. México: Taurus.

Garibay, A. (1953-1954). Historia de la literatura nábuatl. México: Porrúa.

Gruzinski, S. (1994). Las repercusiones de la conquista: la experiencia novohispana. En C. Bernard (Comp.), Descubrimiento, conquista y colonización de América a quinientos años (pp. 148-171). México: Fondo de Cultura Económica.

Gruzinski, S. (2007a). El pensamiento mestizo. Cultura amerindia y civilización del Renacimiento. Barcelona: Paidós.

Gruzinski, S. (2007b). La colonización de lo imaginario. Sociedades indigenas y occidentalización en el México español. Siglos XVI-XVIII. México: Fondo de Cultura Económica.

Inoue Okubo, Y. (2000). Tesis sobre el culto al dios único en la época prehispánica: según dos cronistas indígenas del centro de México. The Journal of Intercultural Studies, 27, 209-221.

Inoue Okubo, Y. (2003). Pomar y Muñoz Camargo en el contexto histórico-historiográfico de la Nueva España. Históricas. Boletín del Instituto de Investigaciones Históricas de la Universidad Nacional Autónoma de México, 66, 2-14.

Inoue Okubo, Y. (2007). Crónicas indígenas: una reconsideración sobre la historiografía novohispana temprana. En D. Levin Rojo y F. Navarrete Linares (Coords.), Indios, mestizos y españoles. Interculturalidad e historiografia en 
la Nueva España (pp. 55-96). México: Universidad Nacional Autónoma de México-Instituto de Investigaciones Históricas.

Las Casas, B. de (2017). Brevísima relación de la destrucción de las Indias. Buenos Aires: Corregidor.

Lienhard, M. (1983). La crónica mestiza en México y el Perú hasta 1620: apuntes para su estudio histórico-literario. Revista de critica literaria latinoamericana, 9(17), 105-115.

Lienhard, M. (1990). La voz y su huella: escritura y conflicto étnico-social en América Latina (1492-1988). La Habana: Casa de las Américas.

Monlau, P. F. (1858). Diccionario etimológico de la lengua castellana. Madrid: Imprenta y Estereotipia de Rivadeneyra. Muñoz Camargo, D. (1998). Historia de Tlaxcala. Tlaxcala: Universidad Autónoma de Tlaxcala.

Pastor, B. (1999). El jardín y el peregrino. Elpensamiento utópico en América Latina (1492-1695). México: Universidad Nacional Autónoma de México.

Pastrana Flores, M. (2009). Historias de la conquista. Aspectos de la historiografía de tradición nábuatl. México: Universidad Autónoma de México.

Pomar, J. B. (1991). Relación de Tezcoco. G. Vázquez Chamorro (Ed.), Relaciones de la Nueva España. Madrid: Historia 16.

Romero Galván, J. R. (Coord.) (2003). Historiografia novohispana de tradición indígena. México: Universidad Autónoma de México.

Torquemada, J. de. (1977). Monarquía Indiana. Tomo IV. México: Universidad Autónoma de México-Instituto de Investigaciones Históricas.

Urrejola, B. (2012). El panegírico y el problema de los géneros en la retórica sacra del mundo hispánico. Acercamiento metodológico. Revista Chilena de Literatura, 2, 219-247.

Vázquez Chamorro, G. (1991). Introducción general. En G. Vázquez Chamorro (Ed.), Relaciones de la Nueva España (pp. 7-15). Madrid: Historia 16.

Velazco, S. (2003). Visiones de Anábuac. Reconstrucciones historiográficas y etnicidades emergentes en el México colonial: Fernando de Alva Ixtlilxóchitl, Diego Muñoz Camargo y Hernando Alvarado Tezozómoc. México: Universidad de Guadalajara.

\section{Notas}

1 Lienhard señala que no existen dichas crónicas en lengua quechua, por las condiciones peculiares de la conquista peruana. En un texto posterior, propone el término "literatura escrita alternativa" para los "códices en escritura glífica con o sin transcripción alfabética, crónicas de todo tipo, títulos, cartas (en lengua indígena, española o latín), etc.” (Lienhard, 1990, p. 11). En estos textos, debajo de su textura "occidental" subyacen "formas de conciencia y voces nativas". Por esto, prefiere este concepto por sobre otros tales como "fuentes etnohistóricas", "visión de los vencidos" o "literatura prehispánica".

2 Juan Bautista Pomar (1527? 1535? - 1590), cronista mestizo hijo de un español (Antonio de Pomar) y de una hija natural de Netzahualpilli, era bisnieto del tlatoani texcocano Nezahualcoyotl. Criado como cristiano, aprehendió las costumbres y tradiciones de su madre. Hablaba con igual fluidez español y náhuatl. Serge Gruzinski sugiere que pudo haber estudiado en el colegio de Tlatelolco, que reunía a indios y mestizos vinculados con la nobleza indígena (2007b, p. 68). Fue escribano de su ciudad natal (Pastor, 1999, p. 428). En Monarquia Indiana Juan de Torquemada plantea la posibilidad de que no haya nacido en Texcoco y que haya hecho uso de esta supuesta jerarquía para reclamar la gobernación de dicha ciudad, cargo que no logró conseguir. Posteriormente, mantuvo litigios legales con sus sobrinos por cuestiones de herencia (Torquemada, 1977, pp. 74-75). Redactó una información de servicios por medio de la cual pretendía el trono de su abuelo, petición que fue tomada en cuenta recién hacia 1602 (Inoue Okubo, 2000, p. 219). En vida sólo obtuvo una parte menor de la herencia, una mansión en la que residió hasta su muerte (Vázquez Chamorro, 1991).

3 Me refiero a los textos de René Acuña (1986), Germán Vázquez Chamorro (1991), Yukitaka Inoue Okubo (2000, 2003) o José Espericueta (2015). No todas estas aproximaciones están en sintonía con el abordaje que pretendo dar a mi trabajo pero es importante destacar algunos de los estudios introductorios y artículos que se dedican específicamente 
a la crónica de Juan Bautista Pomar. Existen, por otra parte, otros trabajos fundamentales para pensar la problemática cronística novohispana, del archivo americano y la enunciación de otras crónicas mestizas (Añón, 2011).

4 Entre los años 1578 y 1585 en Nueva España corregidores y alcaldes mayores convocaron a los responsables de los pueblos indígenas para responder un cuestionario que había sido elaborado por el cronista y cosmógrafo del rey, Juan López de Velasco, en 1577. Dicho cuestionario se componía de cincuenta capítulos divididos, a su vez, en varias preguntas cuyo conjunto abordaba más o menos todos los aspectos del mundo colonial (toponimia, flora, fauna, clima, recursos de los pueblos, distancias, lenguas, historia política, entre otras). El texto fue conocido como "Instrucción y Memoria de las relaciones que se han de hacer para la descripción de las Indias, que su Majestad manda hacer, para el buen gobierno y ennoblecimiento dellas".

5 Juan Bautista era hijo de la hija del tlatoani Nezahualpilli (o Nezahualpitzintli), hijo de Nezahualcoyotl. Tlatoani: señor, gobernante, autoridad, abogado, defensor, dirigente, orador (Diccionario Nauatl-Español, 2001, p. 105). Prefiero la forma en náhuatl ya que para los pueblos amerindios el tlatoani estaba dotado, además de para el ejercicio del gobierno, para la persuasión a través de la palabra, como se desprende de la definición. Por eso, no sería correcto considerarlo sinónimo de la forma occidental "rey”. Uso, también, su forma plural tlatoque.

6 En esta etimología confusa, algunos interpretan "El lugar de la olla de maíz”, otros "Jarilla de los riscos” y otros "Lugar con tráfico y multitud de gentes” (Pomar, 1991, p. 20).

7 "Del griego paneguris o panegyris, proviene de pan, 'todo', y agyris, 'asamblea'; literalmente, 'toda la asamblea'. Discurso pronunciado con gran pompa y aparato, a asamblea general y pública, en loor u honra de alguna persona ilustre. El panegírico puede dirigirse a un personaje difunto, o vivo aun; y en esto se diferencia de la oración fúnebre" (Monlau, 1856, p. 361). En oratoria, el panegírico es el discurso o sermón en alabanza de alguien o un elogio enfático de algo o alguien (DRAE, 2017). Como afirma Emanuele Cesareo (1936), el panegírico se origina en la antigua Grecia, fundamentalmente con las composiciones de Isócrates y Teócrito y se continúa en Roma con Virgilio, Horacio, Ovidio y Catulo. En Roma, el panegírico es un poema breve en hexámetros o un relato en prosa protagonizado por un personaje de condición elevada, contemporáneo del poeta. Algunos elementos que lo constituyen son la presencia de los ilustres antepasados (genus) y del mérito o valor (virtus). Además, el panegírico se cultiva en un ambiente cortesano o noble y hace uso del topos de modestia. En algunos casos, como en el "Panegírico de Mesala" (atribuido a Tibulo), se celebran las dotes militares del pueblo (Álvarez, 1998, pp. 153-157). Cesareo explica las partes del panegírico: exordium, propositio, peroratio, epílogo (1936, p. 64). Bernarda Urrejola sostiene que el panegírico forma parte de la retórica eclesiástica y es un discurso que se caracteriza por producirse en una ceremonia o celebración pública y señalar las virtudes del homenajeado. En contraste, también puede utilizarse para criticar las virtudes opuestas a las promovidas. Dicho elogio puede dirigirse hacia un personaje conocido, histórico, vivo, difunto o un ser celestial. Por eso, "más que un tipo o género de sermón, es una estrategia retórica transgenérica, útil a la finalidad deliberativa de la predicación”. Puede estructurarse como narración, descripción o como combinación de ambas. El panegírico tiene la capacidad de funcionar de manera transversal en todas las manifestaciones de oratoria sagrada, pues constituye un estilo o una modalidad del discurso. Puede, por ende, presentarse en cualquier tipo de prédica y en cualquier situación discursiva, dentro o fuera del ámbito religioso (2012, pp. 240-244).

8 En referencia al mundo posconquista, señala Gruzinski que “el caos no fue sólo político, social y físico, sino que erosionó profundamente el tejido cultural y mental" (1994, p. 156). De aquí que prefiera el término "conglomerado" a "sociedad colonial”, dado que este último supone un estado de acabamiento y de estabilidad inexistente en los años que siguieron a la conquista (Gruzinski, 2007a, p. 86). También usa el término "fractal" para referirse a las formas sociales extrañas que surgen con la conquista. Lo fractal (término proveniente a la física y la matemática) refiere a los fenómenos irregulares y/o fragmentados que no pueden concebirse como una forma entera. Por eso, una sociedad fractal es una sociedad en transición, caracterizada por el caos, la inestabilidad, la heterogeneidad y la hibridez. Por nacer del choque de la conquista, estas sociedades "fractales" son profundamente mutiladas (Gruzinski, 1994, p. 151).

9 Una denuncia similar encontramos en la Historia de los indios de la Nueva España (1541) del fraile franciscano Toribio de Benavente, más conocido como Motolinía. La asociación al tratamiento de los indígenas "como esclavos" nos recuerda a las denuncias lascasianas, fundamentalmente a la Brevisima relación de la destruición de las Indias (2017). Muchos mestizos (y muy probablemente Pomar, entre ellos) habían recibido instrucción por parte de los misioneros (fundamental, pero no únicamente franciscanos) y, en muchos casos, habían actuado como informantes para la redacción de las crónicas de los mismos frailes. 